Article

\title{
Understanding Global Food Surplus and Food Waste to Tackle Economic and Environmental Sustainability
}

\author{
Ching-Hsu Huang ${ }^{1, *}$, Shih-Min Liu ${ }^{2, *}$ and Nai-Yun Hsu ${ }^{1}$ \\ 1 Department of Hotel and Restaurant Management, National Pingtung University of Science and Technology, \\ Pingtung 91201, Taiwan; e521130123@gmail.com \\ 2 Department of Education, National Kaohsiung Normal University, Kaohsiung 80201, Taiwan \\ * Correspondence: chinghsu@mail.npust.edu.tw (C.-H.H.); sml206@nknucc.nknu.edu.tw (S.-M.L.)
}

Received: 8 March 2020; Accepted: 3 April 2020; Published: 5 April 2020

check for updates

\begin{abstract}
Although food surplus and food waste issues are extremely important, the amount of literature published on these topics is astonishingly low by our observation. The relationships between food surplus/food waste and economic/environmental sustainability have not yet been holistically assessed and discussed. The main purpose of this study is to understand global food surplus and food waste issues in order to tackle the economic sustainability and environmental sustainability crisis. Content analysis was used to analyze 500 relevant materials and was conducted by NVivo 12 Plus software. The results contain seven countries, six organizations, and six continents, providing a framework to recognize the economic and environmental sustainability crisis. In addition, six major organizations and regions were identified and were found to be relevant to the important issues of food surplus, food waste, the sharing economy, economic sustainability, and environmental sustainability. With the trend of globalization, this study highlights some preliminary evidence for reducing food waste, for conflicts of the sharing economy, and for regulated sustainability. Further research and regulations in terms of economic and environmental sustainability are strongly suggested.
\end{abstract}

Keywords: food surplus; food waste; economic sustainability; environmental sustainability; sharing economy; hospitality industry

\section{Introduction}

Currently, in society, owing to excessively convenient food accessibility, rapid development, progressive prosperity, and trends in developed countries, many issues relating to food waste and food surplus have emerged, and the situation is deteriorating. According to the statistics of the Food and Agriculture Organization of the United Nations (FAO), roughly one-third of food produced for human consumption is lost or wasted globally, which equates to approximately 1.3 billion metric tons per year [1]. Such a large amount of food waste provokes environmental and social burdens, such as social structure problems, overexploitation of land, economic ills, food security issues, the greenhouse effect, and unequal global food distribution [2]. Furthermore, according to the statistics database of the Environmental Protection Administration, 46,000 metric tons of food waste were recycled in October 2016 in Taiwan, and the quantity of food surplus in the same period would be more excessive if unrecycled food waste was taken into account.

As shown in the predictions of global food waste in Figure 1, the quantity of global food waste is growing rapidly. By 2050, the quantity of food waste is projected to be more than twice the current amount. Moreover, the demand for food worldwide is expected to increase annually, which will force increases in agricultural output [3]. This demand for food could be satisfied only when $70 \%$ of the land area on earth is used for agricultural production, which would force farmers to expand the agricultural land area or to utilize genetic modification techniques to increase output per unit. Such measures, 
however, will not only damage the ecological environment, but will also cause regions of ecological diversity to disappear [4]. Challenged by a number of major crises, such as global wars and climate change, humans will face critical food shortages in the future. An unprecedented food crisis may be faced worldwide if food surplus and waste issues remain unsolved [1].

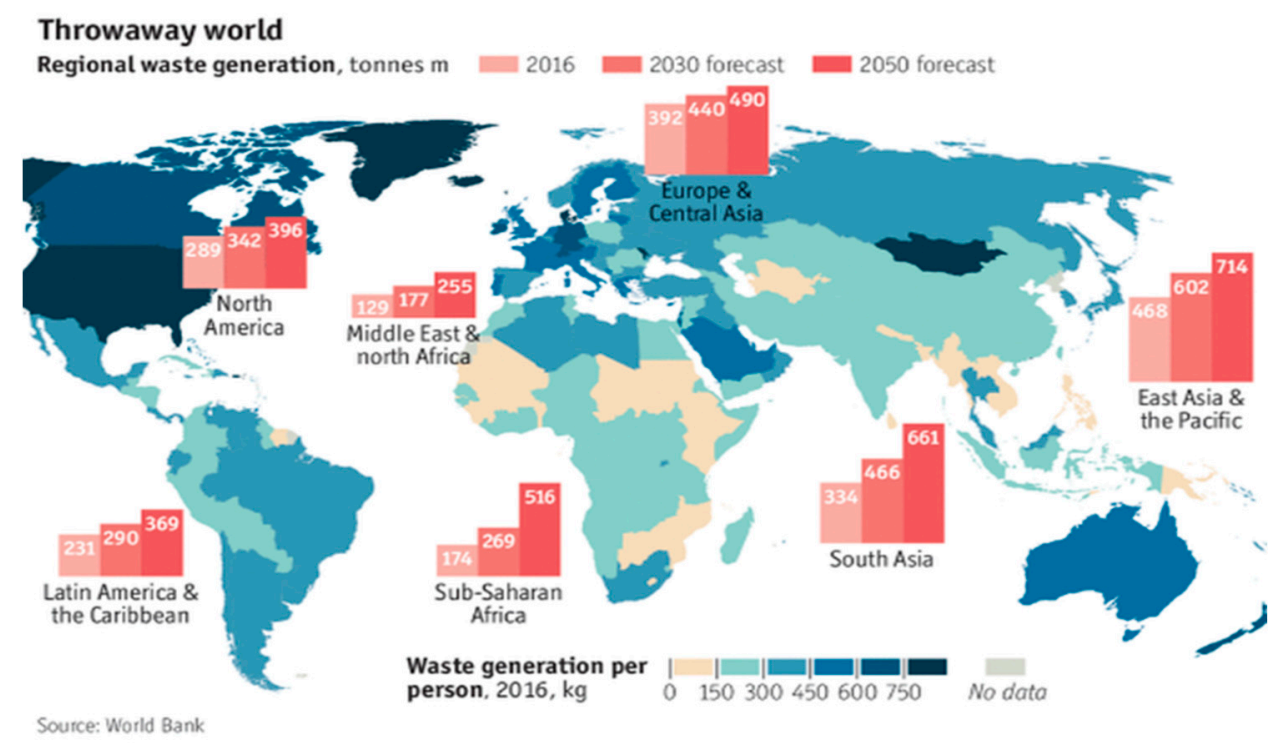

Figure 1. Global food waste distribution and forecast. Source: World Bank (2016).

According to the FAO [5], food waste in developed countries (such as Germany, Italy, the U.S.A., Japan, and Taiwan) generally occurs at the retail and consumption stages. When peoples' living standards are improved, enterprises will adjust product size to cater to customer psychology or will remove large amounts of edible parts in pursuit of high-quality products. Therefore, vegetables, fruits, and other food are wasted due to their shape or expiry date, as well as other similar reasons. Food waste issues are of great importance presently and are a growing concern for many countries worldwide. There is already considerable research investigating food material waste from origin to retailers [6], and the zero food waste strategy has been developed by restaurant management. Massimo Bottura, a famous chef, opened a food surplus kitchen called "Refettorio" in London and designed the "Internet of Things (IoT) Food Cloud" based on information integration technology as an effort to provide platforms available for enterprises or people to utilize edible vegetables and food. Moreover, Lean Path food waste prevention technology has helped restaurants in Google Park save more than 455 tons of food by applying big data analysis [7].

The catering industry is involved in the production and preparation of food and meals and the supply of food for consumption. Food waste in the catering industry mainly occurs in the production and preparation stages [8]. In this industry, all production and preparation processes are closely related to food. Therefore, the catering industry is prone to food waste. According to the statistics of the Taiwan Institute of Economic Research, there is a total of 36,906 enterprises in the catering industry in Taiwan (including the food industry, outside catering, the canteen contracting industry, and the beverage industry); the quantity of food waste produced by the kitchen of a hotel accounts for $36 \%$ of the total quantity of waste produced by the hotel [9]. A large quantity of food waste could be avoided if effective food surplus management was executed by restaurant management and during preparation in the kitchen.

The current literature and research on food surplus/waste are neither popular nor complete, and little related foreign research has been published since 2018. Furthermore, most of the existing research is limited to engineering or biological decomposition, and little research has focused on academic discussions of the food waste issue in the hospitality industry. Accordingly, this study collected and summarized data from the literature on global food surplus/waste and mitigation 
strategies, investigated the overview of food surplus/waste in the hospitality industry, presented a case study of restaurants (paying attention to the food surplus issue), and analyzed further details related to food surplus/waste. In view of the above, the purpose of this study is to understand the current situations and views on food surplus/waste globally in order to tackle the economic and environmental sustainability crisis and to unpack the controversies around food waste in Taiwan.

\section{Literature Review}

\subsection{The Definition of Food Surplus}

When we refer to food waste or food surplus, we often get confused with other related proper nouns. Food surplus or food waste have different definitions when considering different aspects. Papargyropoulou, Lozano, Steinberger, Wright, and bin Ujang [6] stated that in the literature on food surplus management in various countries, the definition of food surplus was not unified; therefore, it was difficult for us to compare such research results in a systematic manner. When the terms in research are not expressly defined and target items are unclear, it is time-consuming and difficult to conduct a relevant analytic comparison. When we can clearly classify food into specific categories, it is easier to analyze food waste from the aspect of improvement controls. Common terms relating to food waste and food surplus are food surplus, food loss, and food waste, as described below.

(1) Food surplus: Due to the overproduction of food in agricultural production processes, excessive amounts of agricultural products imported by a government, weather effects, and market prices impacting farmers' decisions in terms of crop choice, there is a post-harvest oversupply, and uneaten vegetables and fruits are discarded before arriving at suppliers, food processing plants, restaurants, and consumers [6].

(2) Food waste: Food waste occurs at the end of the food supply chain (retail and consumption), as restaurants misestimate the purchase quantity, which causes food spoilage; retailers purchase excessive amounts of vegetables and fruits for promotions; oversized meals are prepared; "best before" dates and validity periods mislead the public to believe that food is inedible after the specified dates; and snack stands make excessive food and place it on shelves to attract customers, but discard such food when it does not sell. Such food waste refers to discarding food that is still edible; therefore, the term "food waste" is a form of intentional discarding behavior [1].

(3) Food loss: Food loss generally refers to any food that is wasted during post-harvest processing or transportation of agricultural products at an early stage of the food supply chain; food that cannot be sold due to pest infestations, shape, improper storage during transportation, and so forth; and food materials being trimmed in order to form them into another shape to meet the standard for production-related reasons. Removal of edible parts for consistency of products is classified as unintentional food waste [1].

\subsection{Food Surplus and Food Waste Issues in the Hospitality Industry}

The majority of people understand the severity of the global food waste issue. Food waste relates to broad aspects in practice. There are many parts in the food delivery process that are prone to food waste, from the cultivation and harvesting of food to the dining table. Food waste is likely to occur at the origin of food materials, during the process of delivery and food selling, and at the food preparation and food consumption locations. From 2010, most research on food waste has been conducted in the United States and the United Kingdom (UK), and most studies have been qualitative in nature. Although scholars and experts know that food waste occurs at the household level as well as at the delivery, processing, and selling levels, most research topics have been limited to food waste at the household level [10].

The catering industry in the hospitality field supplies food for consumers and is the industry where the highest possibility of food waste occurs with respect to the food preparation and eating behaviors of consumers. The severity of the adverse effects of the waste produced by the hospitality 
industry on the environment has been gradually identified by the public and scholars, who have pointed out that this is an increasingly serious issue for which we require an in-depth understanding, alongside discussions regarding addressing issues relating to the large amount of waste produced by the hospitality industry. Pirani and Arafat [11] and Pham Phu, Hoang, and Fujuwara [9] stated that the waste caused by the kitchen of a hotel accounts for $36 \%$ of the total amount of waste produced by the hotel. Many scholars have also implemented research on food waste or surplus in the hospitality industry $[9,12,13]$.

Kallbekken and Salen [14] reduced the portion size of meals in the Chinese restaurants of 52 hotels and used this experimental design to understand customer food waste behavior. Their research results show that reducing meal size could significantly reduce the quantity of food waste. This research can be considered early academic research into factors relevant to the hospitality industry. Pirani and Arafat [13] verified the food waste issues and strategies for restaurants in Abu Dhabi by combining qualitative and quantitative methods. This research targeted three major types of catering industries in hotels, including restaurants and buffets. Information on the situation and quantity of food waste was investigated and collected, mainly by the food circulation method $[13,14]$, to identify factors that were the main causes of food waste. Their research results showed that the meal service model, time, and category of meals predicted the consumption quantity of consumers, and they also found other factors that influenced food waste in restaurants [13]. The FRESH (Food Waste Rating for Events vis-à-vis Sustainability in the Hospitality Sector) formula was proposed after research analysis, which can potentially be used for assessing and comparing the quantity of food waste generated from global catering service activities. This quantity is a value deduced from five indicators, namely show-up, planning, portion size, economy of scale, and reuse. A smaller figure obtained through this calculation represents a lower severity of food waste.

Papargyropoulou et al. [12] stated that food waste is a topic that has only recently been confirmed for research, as Garrone et al. started research on solutions to food waste in 2014. So far, however, most research on food waste has been limited to the household level and the food marketing industry, as well as broad research at the engineering and technical levels. For example, Kuczman et al. [15] applied the anaerobic digestion method to discuss and resolve the food waste crisis that restaurants in southern Brazil had been facing. This topic was discussed at the chemical level. A series of biodegradation procedures conducted by microorganisms in an anaerobic environment can be partially applied in a comprehensive waste management system. Reductions in food waste, rubbish, and gas emissions are other benefits of applying the anaerobic digestion method [15]. Little research has discussed food waste from a theoretical perspective. Accordingly, scholars conducting this research have proposed a research model in relation to producing and preventing food waste by qualitative and quantitative research methodologies [12]. In this study, a case study of a restaurant in a hotel was discussed, involving food procurement from suppliers, food storage, food preparation, and consumption by consumers at the dining table, in an effort to apply the research model to restaurants' food waste [12]. This food waste model connects to the biophysical and economic flow surfaces for a discussion of the influential factors in relation to social and cultural issues in the process of food preparation and consumption. Research results have also demonstrated an important correlation between food preparation and delivery processes, as well as consumers' consumption behaviors [12,14,15].

Selin [16] confirmed the importance of food waste with respect to the food waste issue in an all-you-can-eat buffet restaurant in the UK and suggested the importance of gaining a full picture of food waste generation points in restaurants by considering the following objects together: Food delivery, food consumption, and the occurrence of food waste. The importance of carbon footprints has also been proposed and discussed in such research [11,12]. Fortunately, in 2017, scholars all over the world started to realize that food surplus and food waste issues should be researched and should not be limited to survey reports. Some scholars started academic research on food surplus or food waste, but it was not widespread at this stage, as there were many difficulties in the actual implementation of the research. Therefore, some scholars could only confirm the factors related to food waste reduction through case 
studies [17,18], experimental manipulation [19,20], or questionnaire surveys [21], and some scholars implemented research into a food process of operation from a restaurant. For example, Filimonau, Lemmer, Marshall, and Bejjani [22] realized that the catering industry has a substantial impact on the environment and society, and accordingly implemented research on the relationship between the design of restaurant menus and food waste by consumers. Restaurant operators are responsible for properly designing a menu that guides consumers to select dishes and sizes correctly. The European scholars Fieschi and Pretato [20] also assessed and discussed the impact of food surplus in restaurants on the environment by applying the European Standard Product Environmental Footprint (PEF) and life cycle of food. The American scholars Hamerman, Rudell, and Martins [23] directly researched restaurant consumers' willingness to take away leftovers in an effort to identify critical factors to predict food surplus in restaurants and reduce the quantity of food waste.

\subsection{The Food Sharing Economy as a Component of Environmental Sustainability}

Food surplus and food waste are key problems that affect economic and environmental sustainability [24]. Heo [25] conducted research on the present situation and outlook towards the sharing economy in the hospitality and tourism industry and indicated that the popularity of the sharing economy in the tourism industry represents consumers' demand for close interconnections among local communities. However, there is hardly any research on how tourists could use the peer-to-peer network sharing economy service model, and there is no assessment of tourists' actual experiences of the accepted value of such a sharing economy model or any comparison of differences and similarities between the peer-to-peer network sharing economy and traditional service model. Richard and Hamilton [24] formed a food surplus exchange market platform, integrating commercial peer-to-peer mutualization systems and sharing economy-based companies. In addition, they also developed a two-sided network-demand model. Their research results show that the secondary market is in more urgent need of such a sharing model, and the standard design of the sharing platform model could enable smoother delivery of food surplus in a secondary market; therefore, food waste would be reduced in an effective manner. Research has also found that the quality of social interactions of the peer-to-peer network sharing economy model and the relationship between tourists and the host of the sharing platform play a vital role with respect to tourists' perceived value and satisfaction. Furthermore, the value perceived by tourists with respect to a sharing economy service may vary with the accumulation of their actual use experiences. Experts and scholars have not yet conducted further research on the service model of the peer-to-peer network sharing economy or on the relationships between responsible tourism and the sharing economy [25].

Food waste has caused sustainable social development and environmental sustainability to fit poorly with economic principles. Therefore, in the catering industry, the sharing economy will play a vital role in achieving sustainability and has been considered as a basic practice that is effective in environmental sustainability and economic conditions [26]. The sharing economy is also new to Europe and America in terms of addressing food waste and includes the use of a collaborative consumption model, such as food sharing, Growington, and Feastly, to reduce the quantity of food waste produced by consumers and retailers. In order to classify food sharing models in the catering industry, Michelini, Principato, and Iasevoli [27] selected 52 food sharing research samples from 91 platforms, most of which were online food sharing platforms and food-sharing-oriented mobile apps. Existing food sharing models were researched by hierarchical clustering analysis to find out how such digital platforms provide diversified food circulation channels and how to change the reuse value of such food in the network world. According to the research results, such models are roughly classified into three types of sharing models, namely money sharing models, public-welfare-oriented sharing models, and community-oriented sharing models. Since most current models are not profit-oriented, whether a profit-oriented sharing economy model will be developed in the future is a topic worthy of further research. 
With respect to strategies to address food waste, people consider food recycling to be a good solution. The catering industry also has to address the food waste issue by gradually transferring its attention from consumers to the exploration and development of food sharing activities. However, scholars have found that food sharing should not be considered as the panacea to mitigate the food waste issue, as food sharing is driven by various social influential factors, and certain special techniques are also required [28]. Morone et al. [29] applied the experimental design method to trace food waste routes, and their results showed that the food sharing economy model cannot directly address the food waste issue, since many factors are involved, such as environmental and economic awareness, local technology, cooperation, and more, all of which may improve the efficiency of the sharing economy model.

\section{Methodology}

This study investigates global food surplus and food waste to tackle economic sustainability and environmental sustainability by using content analysis. The implementation stages of this study are summarized in Figure 2. The advantages of qualitative content analysis are the richness of data collection, coding in a valid way, and interpreting in a reliable way [30]. Data are coded based on the literature reviews, and each text relies on the performance of manual annotation. They include food waste, food surplus, countries, regions, organizations, and others.

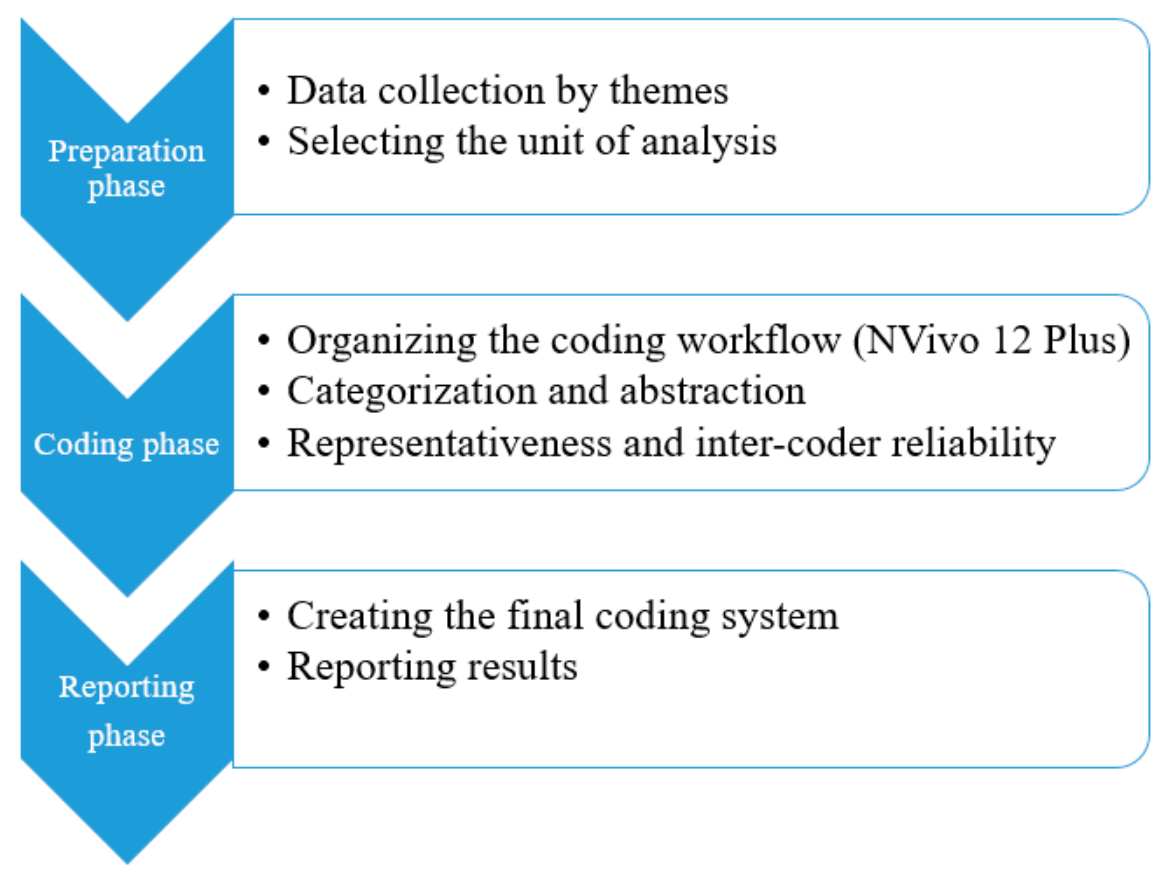

Figure 2. The research methodology process.

\subsection{Data Preparation}

There are four stages of data preparation: Identifying, unitizing, preparing, and storing the data. The number of words required per unit is largely dependent on the concept-related themes. Since the main focus of this research is on food surplus and food waste, this study collected data by using themes, including food surplus and food waste, in both English and Chinese. In order to collect the most suitable data for content analysis and the research questions of interest, Google Chrome and Google Scholar were browsed; these platforms offer access to a random sample of the full population for collecting content to be posted, according to themes. Google is the most popular search engine worldwide, with an $81.5 \%$ market share. [31]. Five hundred materials of different types were collected, including digital news articles, research papers, reports, press releases, and others. 
After data identification and storage, 500 materials were regarded as basic text documents. Extraneous text in a document can result in false inferences; hence, data cleaning is vital [32]. Data cleaning in this study consisted of two phases. The first was error detection, and the other was error repairing, including identifying duplicate records in English and Chinese, detecting violations of functional dependencies, spell-checking, replacing abbreviations, eliminating emotions, and removing typos, asterisks, and other signs that cannot be recognized by NVivo 12 Plus [33]. After the basic text documents were cleaned, they were segmented into units. Since the output might be aggregated upward, this study manually segregated the data into minimum units of comparison using coders. Unfortunately, the inter-coder reliability was not good enough. Therefore, this study took advantage of NVivo 12 Plus for auto-coding and automatic classification. Eventually, using one text file for each unit of analysis, this study created a clearly organized file structure. After the data had been prepared and stored, this study operationalized the constructs. Since this study wanted to study global food surplus/waste with economic and environmental sustainability and did not know how exactly they were to be discovered and differentiated from each other, this study used a classification approach in which this study first identified three categories of text and then analyzed recurring patterns within these sets.

This study took advantage of NVivo 12 Plus to utilize and segregate data within the file automatically by sentence, paragraph, or a unique string of text through codes. By automating the process of unitization, Table 1 shows the results of data extraction in terms of regions, organizations, and countries. It shows the number of documents available for each case in both frequencies and percentages. Six regions were included: Europe, America, Asia, Africa, the Middle East, and Oceania. Based on the analysis, 11 organizations were identified, and this study discarded organizations that had fewer than 30 documents available. In addition, 20 countries were identified, and the countries that had fewer than 50 documents were discarded. In summary, six regions, six organizations, and seven countries were sorted for further analysis regarding the five major issues, which were also extracted at the same time and included food surplus, food waste, the sharing economy, economic sustainability, and environmental sustainability.

Table 1. Data extraction of regions, organizations, and countries.

\begin{tabular}{|c|c|c|c|c|c|c|}
\hline No. & Regions & Counts $(\%)$ & Organizations & Counts (\%) & Countries & Counts $(\%)$ \\
\hline 1 & Europe & $239(47.8)$ & FAO & $202(40.4)$ & UK & $229(45.8)$ \\
\hline 2 & Americas & $237(47.4)$ & European Union & $95(19.0)$ & $\begin{array}{l}\text { United } \\
\text { States of } \\
\text { America } \\
\text { (USA) }\end{array}$ & $214(42.8)$ \\
\hline 3 & Asia & $165(33.0)$ & $\begin{array}{c}\text { Organization for Economic } \\
\text { Cooperation and } \\
\text { Development (OECD) }\end{array}$ & $50(10.0)$ & Italy & $133(26.2)$ \\
\hline 4 & Africa & $31(6.2)$ & World Resources Institute & $46(9.2)$ & China & $99(19.8)$ \\
\hline 5 & $\begin{array}{l}\text { Middle } \\
\text { East }\end{array}$ & $12(2.4)$ & FareShare & $30(6.0)$ & Taiwan & $99(19.8)$ \\
\hline 6 & Oceania & $10(2.0)$ & World Bank & $30(6.0)$ & India & $66(13.2)$ \\
\hline 7 & & & $\begin{array}{l}\text { Restaurant Food Waste } \\
\text { Action Guide (ReFED) }\end{array}$ & $18(3.6)$ & Turkey & $53(10.6)$ \\
\hline
\end{tabular}

\subsection{Data Analysis and Reliability}

A huge number of materials were available in digital form; to be able to process the large volume of digital materials, computer-assisted text analysis was adopted in this study. Figure 3 displays the workflow of "NVivo 12 Plus-assisted workflow of content" analysis. An automatic coding process can result in a fully coded base population, giving researchers the chance to reveal category frequencies and proportions with respect to meaningful sets. 


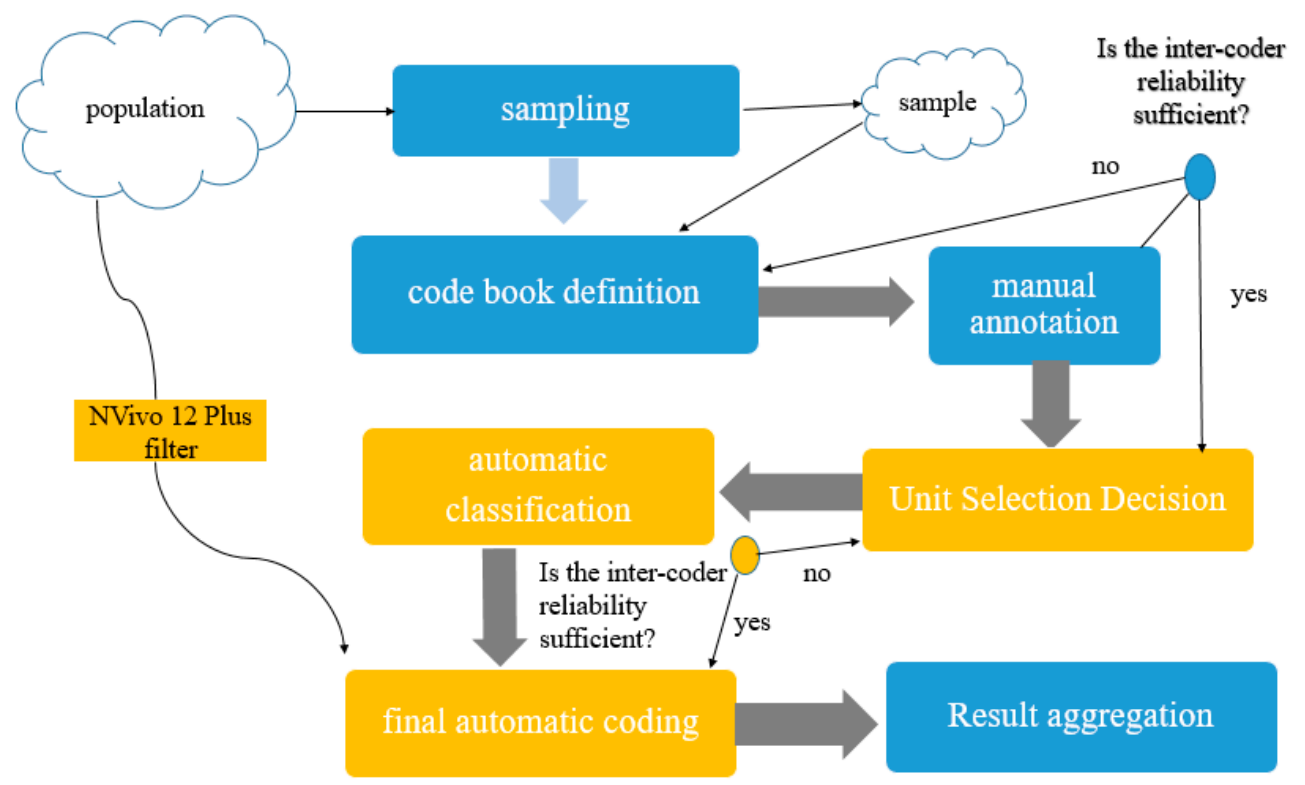

Figure 3. Data analysis workflows assisted by NVivo 12 Plus.

Classification approaches were used in this study while dealing with the constructs of food surplus/waste that might be more latent in the text. In other words, the operationalization of the constructs still could not be hypothesized. The reasons for using the classification approach for data analysis were because this approach reduced the amount of human coding and also revealed insights that might be buried in the large amount of data [31]. This study classified materials based on the regions, organizations, and countries they pertained to, using sustainability to determine the most related issues, and then discovered the patterns. This study theorized as to why the relationships had connections.

In order to ensure reliability and reduce the possible biases, this study undertook the coding comparison with two different coders [34]. After NVivo 12 Plus proceeded with the coding comparison, the agreements, disagreements, and Kappa coefficients were calculated to verify inter-coder reliability. The inter-coder coefficient was between 1 and 0 . If the two coders totally agreed with each other, the Kappa coefficient $(\mathrm{k})=1$; if they attained some agreement with the other but did not fully agree, then $(\mathrm{k}) \leq 0$. Landis and Koch [35] asserted a starting point of the Kappa coefficient range $(\mathrm{kr})>$ 0.80 as "almost perfect" $0.61-0.80$ as "substantial", $0.41-0.60$ as "moderate", and $0.21-0.40$ as "fair". Therefore, if the agreement was greater than 0.80 , this meant the comparison was deemed perfect; if it was below 0.60 , the researchers had some disagreement and needed to proceed to peer debriefing again. The results of inter-coder reliability are shown in Table 2 . This study discarded nodes for which the agreement values were less than $80 \%$. The overall average of inter-coder reliability was $98.46 \%$.

Table 2. Results of inter-coder reliability.

\begin{tabular}{ccccc}
\hline Nodes & Kappa & Agreement (\%) & A and B (\%) & Not A and B (\%) \\
\hline 1 & 1 & 100 & 0 & 100 \\
2 & 0 & 92.95 & 0 & 92.95 \\
3 & 1 & 100 & 0 & 100 \\
4 & 1 & 100 & 0 & 100 \\
5 & 0 & 15.74 & 0 & 15.74 \\
6 & 0 & 79.45 & 0 & 79.45 \\
7 & 0 & 70.88 & 0 & 70.88 \\
8 & 1 & 100 & 0 & 100 \\
9 & 1 & 100 & 0 & 100 \\
10 & 0.5 & 93.17 & 0 & 93.17 \\
\hline
\end{tabular}




\section{Results}

\subsection{Major Classifications of Food Surplus/Waste and Sustainability}

Frequency analysis was used in this research in order to discover issues with the highest repetition rate from the materials searched. The most frequently used words and terms in the texts are shown in Figure 4, based on auto-coding skills. The font sizes of the words in Figure 4 represent the frequency with which they appeared in the text files; a larger font size indicates a higher frequency of appearance. The different colors of the words are only used for recognition. The results showed that the top ten most frequently used words were food waste, production, food surplus, management, countries, environmental, consumption, household, world, and economic. The counts (and weighted percentages) of the three top-frequency terms were 73,331 (2.74\%), 39,092 (1.46\%), and 8803 (0.33\%), respectively. The weighted percentages are calculated automatically by NVivo 12 Plus's Wizard to arrange in a way that is likely to produce a particular effect. In addition, the results of the auto-coding showed some other interesting terms, including sustainable, energy, research, agricultural, international, consumer, anaerobic, global, resources, digestion, university, and prevention. The quantity of global food waste is 1.300 million metric tons, including an average of 95-115 kilograms per person per year in Europe and America, and an average of 6-11 kilograms per person per year in sub-Saharan Africa, South Asia, and Southeast Asia. According to the data, 40\% of food loss in developing countries occurs at the collection, processing, and preparation stages. Food loss in developed countries occurs at the retail and consumption stages; that is, food waste has already been caused to various extents before customers purchase products [1]. Food waste is not only a moral and economic issue, but also depletes limited natural resources in the environment. Sustainable development goals can be achieved by reducing food loss and waste. After the materials were sorted, the results in terms of the matrix coding of regions, organizations, countries, and issues are presented below.

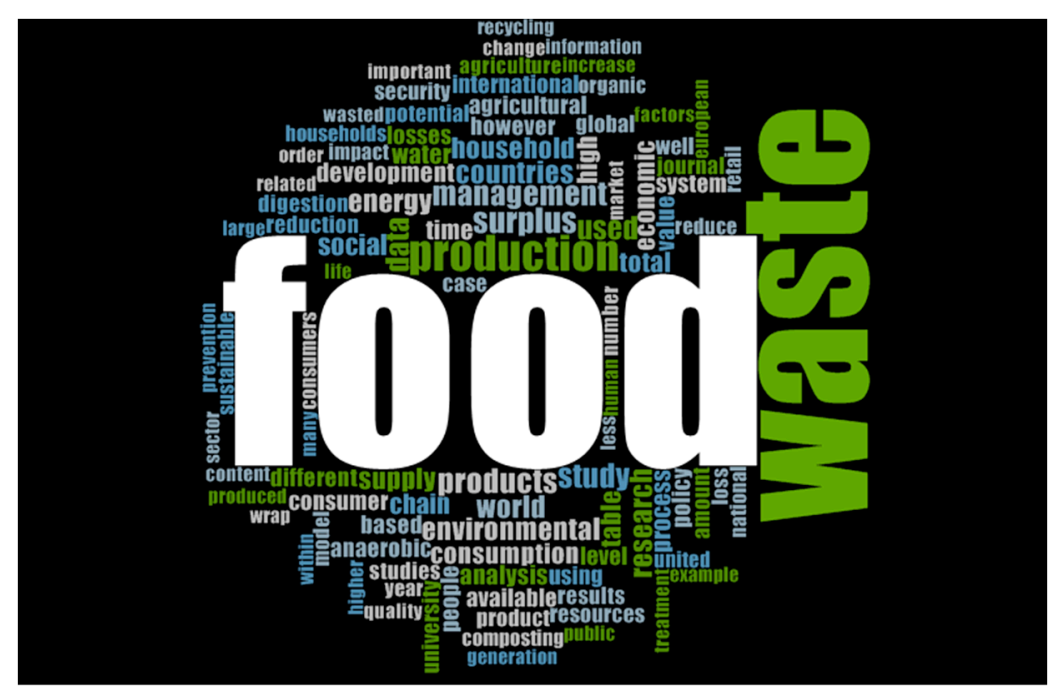

Figure 4. The most frequently used words and terms.

\subsection{Matrix Coding of Regions and Issues}

Figure 5 illustrates the cross-relationships between six regions and important issues. The y-axis in Figure 5 is the coding reference count. According to the frequency of content (e.g., the number of words and sentences) in each document, Europe has the highest term frequency with respect to food waste (768 counts), food surplus (57 counts), economic sustainability (8 counts), environmental sustainability (7 counts), and sharing economy (4 counts). America has the second-highest term frequency, and the counts of terms are as follows: Food waste, 441; food surplus, 38; economic sustainability, 1; environmental sustainability, 7; sharing economy, 4. Asia has the third highest 
term frequency, and the counts of terms are as follows: Food waste, 226; food surplus, 9; economic sustainability, 0 ; environmental sustainability, 3 ; sharing economy, 0 . The rest of the regions, the Middle East, Africa, and Oceania, show no counts in economic sustainability, environmental sustainability, and the sharing economy. In summary, few works have been published relating to the sharing economy, economic sustainability, and environmental sustainability in many countries, while Europe is considered to be the pioneer in research on food waste, food surplus, the sharing economy, economic sustainability, and environmental sustainability.

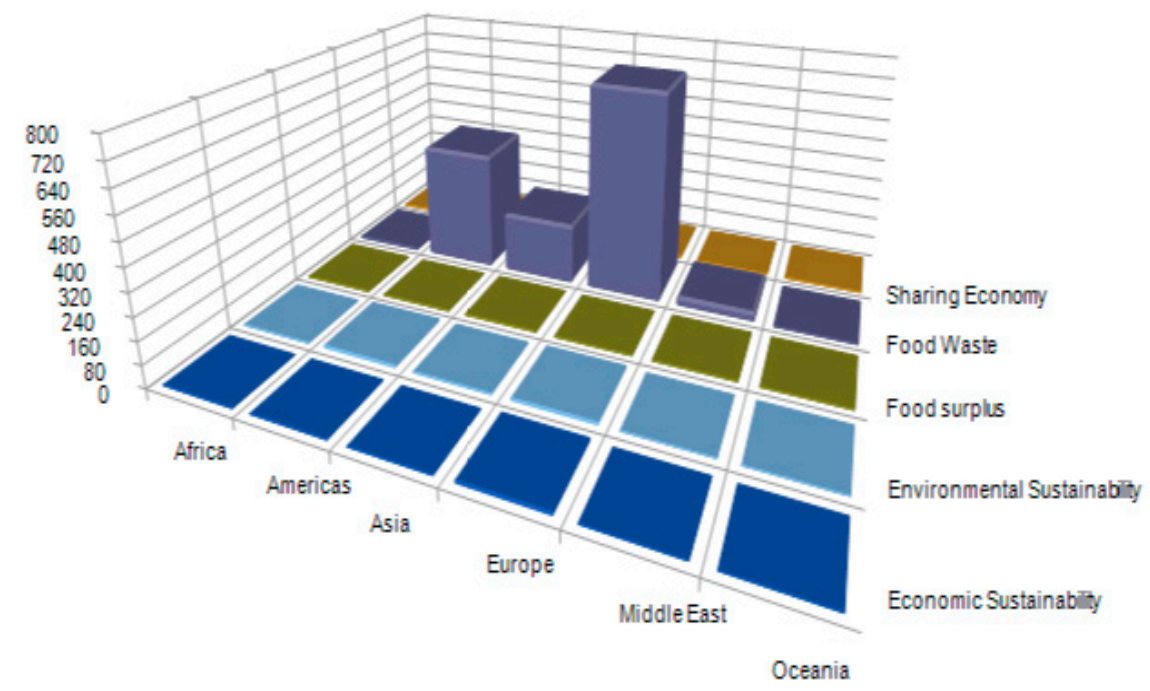

Figure 5. The matrix coding of regions and issues.

In Europe, France and Italy have officially passed the "Anti-Food Waste Act", pursuant to which food suppliers must donate surplus food and products to charities through cooperation agreements [36], and if any unauthorized food surplus destruction occurs, a fine of 3750 Euros (EUR) can be imposed [37]. Additionally, Germany has changed laws around food date labeling. Currently, in Germany, the food labeling that is being canceled is mainly against long-term-storage foods such as salt, sugar, vinegar, rice, and noodles. Such foods are now marked with the production date, and the expiration date is no longer shown, so as to allow consumers to determine for themselves whether the food is still edible. However, certain perishable fresh foods (such as fresh meat and milk) must still be marked with a "best before" date [38].

In Denmark, a mobile app called "Too Good To Go" was designed in order to save leftovers that would otherwise be dumped into dumpsters, providing them to those in need at a relatively low price. Users may buy a leftover meal with price ranges of only around 2-3.8 Great British Pounds (GBP) as long as they are registered, with the additional condition that they will need to collect the food at a certain time-generally after business or peak hours of restaurants. The users cannot place specific orders, and the only information they have is the type of food they ordered. In addition, the "leftovers" that they ordered are not the food left by customers; instead, it may be the cooked food that did not sell. In Ireland, a social enterprise built a platform called Food Cloud, aiming to reduce food waste in the food retail industry through big data and in cooperation with Tesco, the largest grocery retailer in the UK. The data-oriented method is significantly different from the general traditional food surplus redistribution method, as it utilizes big data technology to identify appropriate social welfare organizations that need such a food surplus; therefore, the Food Cloud platform can collect data on various types of food surplus and can even measure the performance of the distribution of the food surplus [39]. 


\subsection{Matrix Coding of Organizations and Issues}

Based on the seven organizations and five issues, Figure 6 shows that the FAO has the highest frequency among the other relationships. The y-axis in Figure 6 is the coding reference count. According to the frequency of each document, the FAO has the highest frequency of the terms food waste (359), food surplus (18), economic sustainability (1), environmental sustainability (4), and sharing economy (1). Unfortunately, the organizations were found to have nothing to do with economic and environmental sustainability.

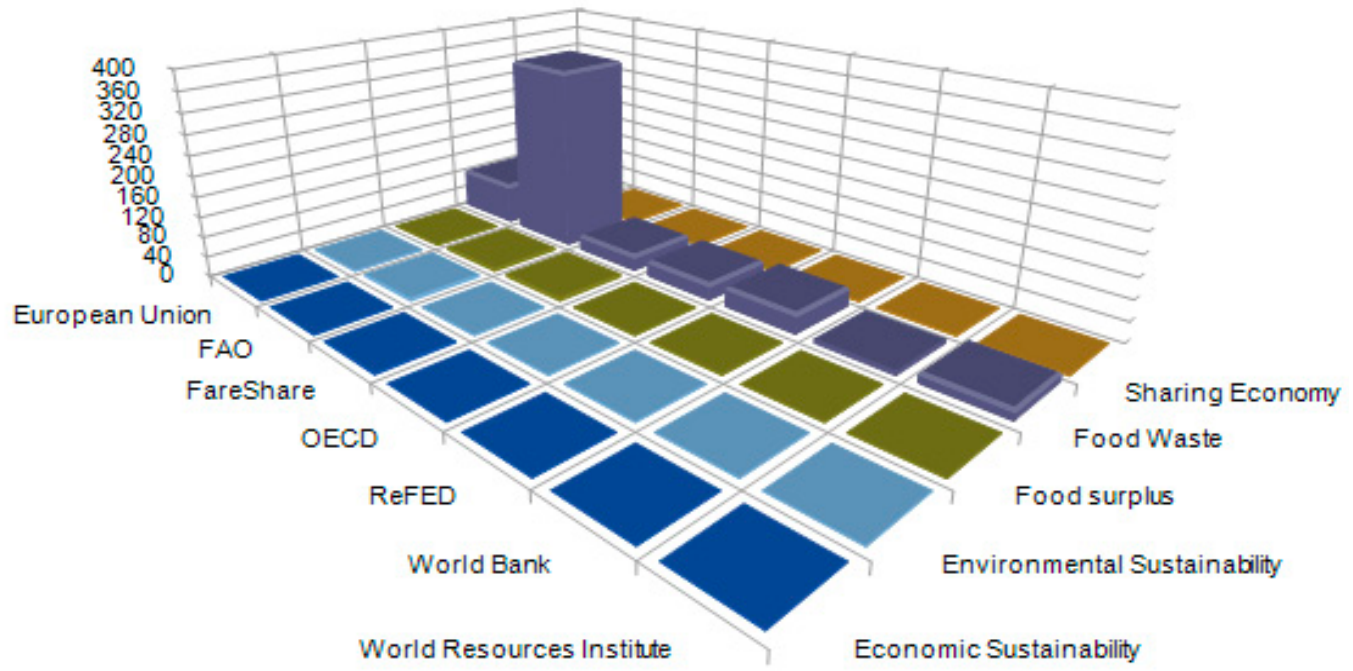

Figure 6. The matrix coding of organizations and issues.

According to the statistics from the European Union, approximately 88 million metric tons of food waste are produced in Europe per year; food with a total value of 700 GBP is discarded per household per year, and the related costs are estimated at 143 billion EUR; the total quantity of food waste across Europe per year is sufficient to support two billion people [40]. European countries have set about understanding the situation and causes of food waste. According to the statistics of the French Environment and Energy Management Agency, the value of food discarded in France each year is equivalent to 16 billion EUR and 15.3 million metric tons of carbon dioxide emissions [41]. Italy is subject to approximately 12,500 million EUR in economic losses caused by food waste; $75 \%$ of its food waste occurs during consumption at the household level or in restaurants [40,42]. In Europe, $15-33 \%$ of food is discarded by people when they fail to properly understand the date marked on the packages, i.e., that the "best before" date means the food has expired [43]; in addition, according to a consumer market survey conducted by the European Union, only 1/3 of consumers understand the meaning of the "best before" date correctly. Even though an estimated one out of ten people in Ireland is struggling with food poverty, 1 million metric tons of food are still discarded by consumers and enterprises in the country [39].

\subsection{Matrix Coding of Countries and Issues}

The results of the matrix coding of countries and the five issues are nearly identical to those of regions and organizations. Most of the countries undertake numerous tasks related to food waste and food surplus, but information on the effects of the sharing economy, economic sustainability, and environmental sustainability is still limited. Therefore, this study used different units to analyze the relationships between countries and issues, including environmental sustainability, economic sustainability, the sharing economy, and others. Figure 7 demonstrates that the United States has the second-highest term frequency of policy and food waste. The $y$-axis in Figure 7 is the coding reference 
count. Based on additional information from the related nodes of the United States, further information relating to food waste and surplus is shown as follows.

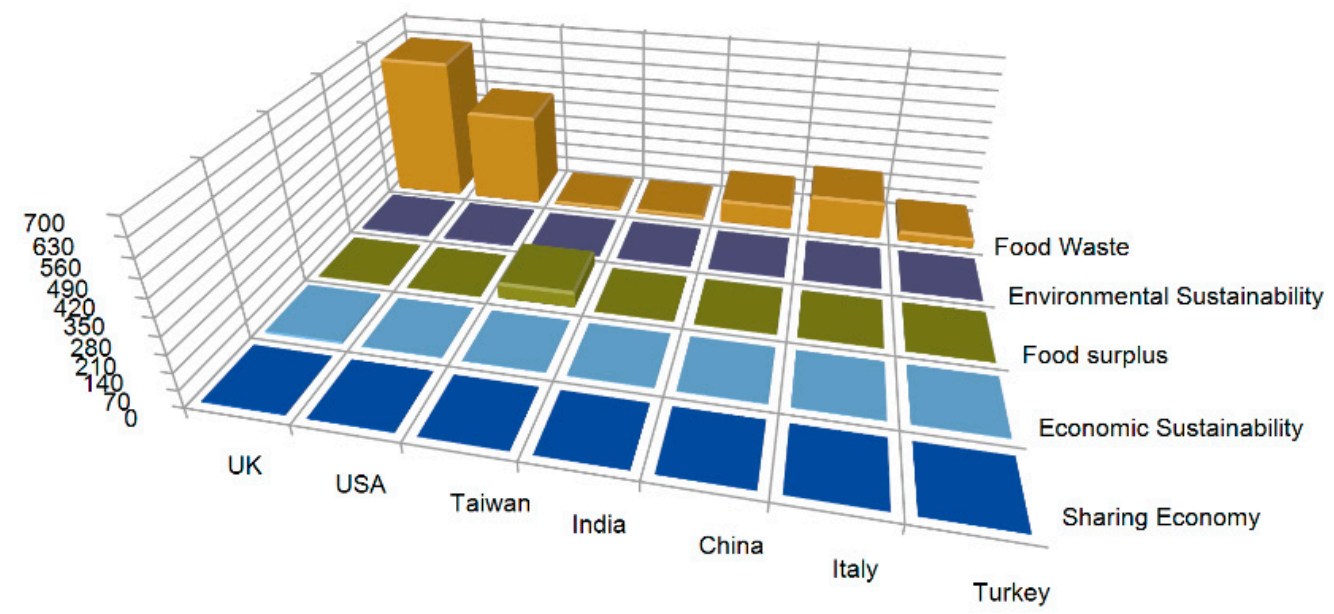

Figure 7. The matrix coding of countries and issues.

According to Gunders [44], 50\% of land in the United States is used for farming and raising livestock, and $40 \%$ of water resources are used for irrigation, but the food produced from this input is not completely consumed. In fact, $40 \%$ of food is wasted, and 20 pounds of food are wasted per capita per month. Vegetables and fruits, seafood, grains, dairy products, and meat account for $45 \%, 35 \%, 30 \%$, $20 \%$, and $20 \%$ of the food wasted, respectively, and such food is wasted at the retail and consumption stages in the second half of the food supply chain [45].

The food waste situation is critical in the United States and can be attributed to the culture and consumption habits of this country. A capitalist society's most consuming concept tends to be shopping, and shopping brings benefits to the economy; however, excessive consumption leads to the purchase of considerable amounts of unnecessary goods or food, and the effect may be worsened by blurry concepts related to edible and inedible food. Figure 8 shows the actions taken by the United States to cope with food waste in terms of the five issues of food surplus, food waste, the sharing economy, economic sustainability, and environmental sustainability since 1970. In 1970, the phrase "edible food" was elucidated by the U.S. Department of Agriculture; in 1980, the United States was involved in opposing the Islamic Jihad Movement. As the country was focusing on military forces during that time period, the anti-war organization "Food Not Bombs" was accordingly formed, in response to the hunger and poverty the war had brought to society. Members of this organization recycled foods that were supposed to be discarded and turned them into freshly cooked meals after re-cooking and provided them to those in need without any charge [46].

Freeganism originated from the hobo subculture during the Great Depression period of the United States. Derived from the anti-globalization movement, freegans advocate zero buying (including food), driving, real estate purchasing, and even working, in pursuit of consuming minimal resources. They simply rely on food in dumpsters to maintain their needs for nutrition, from food with slight defects to cans that are discarded daily by supermarkets and restaurants due to passing expiration dates. Sometimes they may seek leftovers without payment at restaurants. They believe that consumers have wasted a large amount of resources, thus producing a large amount of waste. Tristram Stuart mentioned in his TED talk that he had realized the severity of the food waste crisis when he was fifteen years old when he discovered fresh vegetables and fruits were being discarded by supermarkets only because they were the wrong shape or size. He collected such food that was still edible for humans and fed it to pigs, which were sold for significant profit once grown. In the United States, newly formed non-governmental organizations or government authorities have committed to reducing the quantity of food waste by developing new policies every year [46]. 


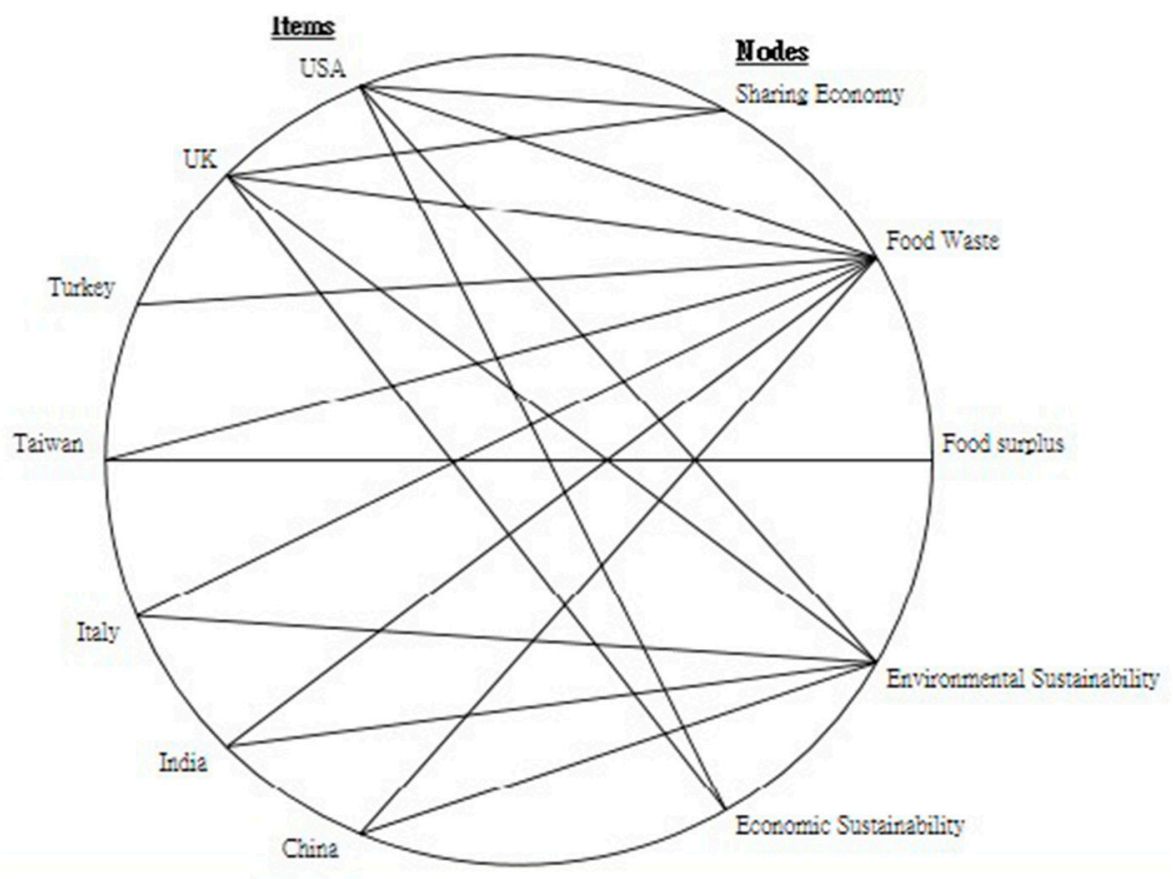

Figure 8. The relationships between countries and issues.

Figure 9 shows the project map of five important issues (food surplus, food waste, the sharing economy, economic sustainability, and environmental sustainability) and their relationships with organizations and countries. This map indicates that the United States and the United Kingdom are the two countries that are involved with all five issues listed. In addition, all of the countries and organizations are related to the United Nations (UN). Policy was found to be an important issue in terms of food surplus, food waste, the sharing economy, economic sustainability, and environmental sustainability.

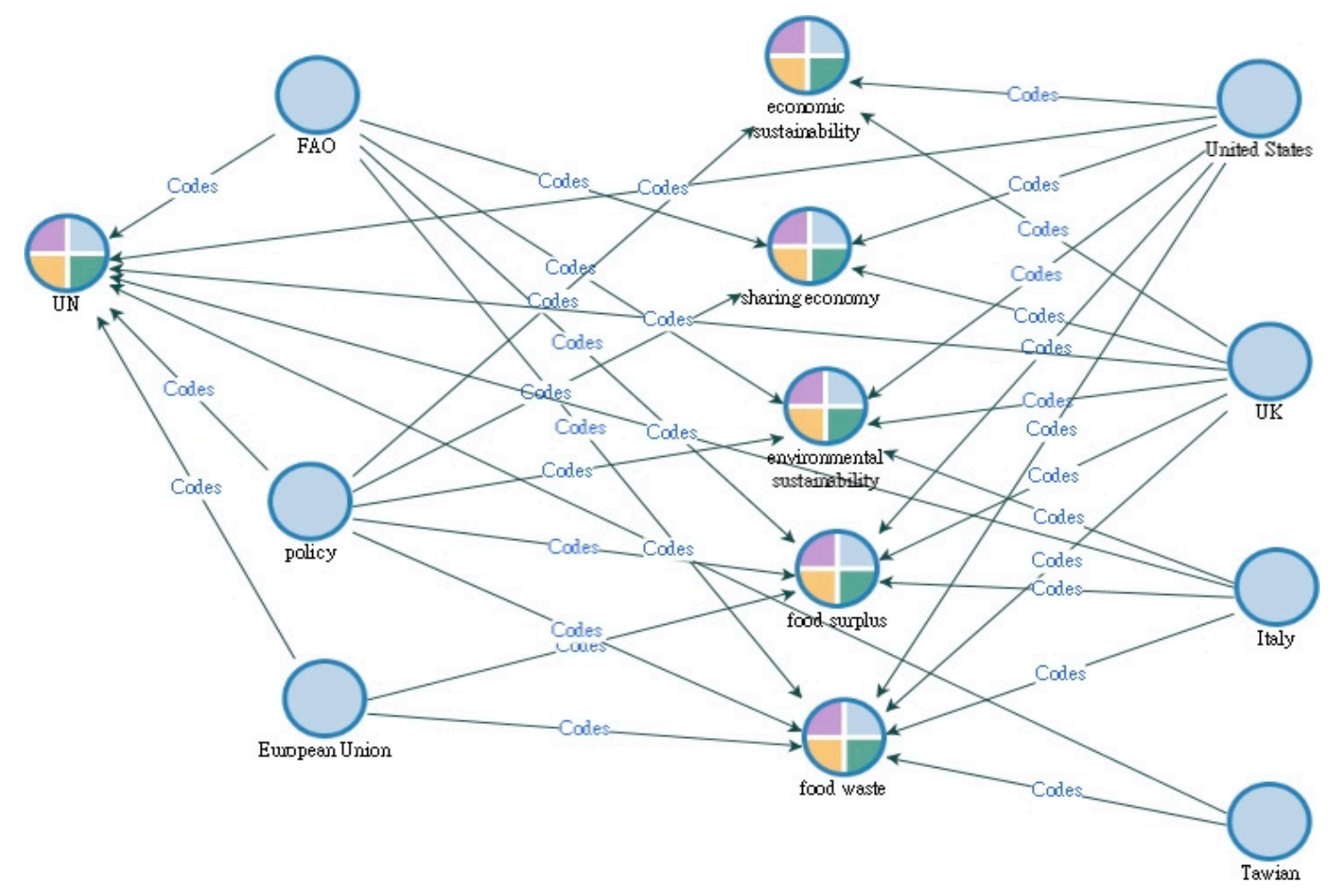

Figure 9. Project map of issues in organizations and countries. 


\section{Discussion}

The results outlined above show that the issues of food surplus and food waste have already been on people's minds for a long time, except for economic and environmental sustainability issues. Governments and people in many countries, including Taiwan, regard food waste as a very important issue. Some of the researchers and experts in industries have started to pay attention to these issues. This study took this opportunity to introduce policy and the situation in terms of food surplus and food waste. In addition, the results may help us to improve in the future by taking small steps towards addressing the issues.

The purpose of this study was to understand the current situations and views on food surplus/waste globally in order to tackle the economic and environmental sustainability crisis and to unpack the controversies of food waste in Taiwan. According to the results, the United States and United Kingdom are two countries focusing a lot of effort on the five identified issues discussed in this paper. The activities or policies in both countries have been addressed in previous texts. This study sought to unpack the controversies of food waste in Taiwan by discussing the sustainability crisis based on global findings. Currently in Taiwan, there is no substantial official government information on the statistical quantity of food waste and food surplus actually being discarded by a variety of stores. Most of the data have been derived from non-governmental and non-profit organizations. In Taiwan, roughly 3080 million New Taiwan Dollar (NTD) of food surplus is discarded by a variety of stores per year, and roughly 730 million NTD of food surplus is discarded by supermarkets per year. Food that is "approaching its expiry date" is defined by operators as food surplus, which is related to operators' considerations of food safety and compliance with laws and regulations; for example, the Enforcement Rules of the Act Governing Food Sanitation, Article 15, states that selling food that has expired is prohibited. This article aims to reduce food safety issues and also cater to customer preference and other factors. Operators generally process food surplus using the following three practices: Selling food surplus to pig farmers as animal feed, discarding food surplus as food waste and incinerating food surplus together with domestic waste, and donations. Currently, there is no explicit regulation in Taiwan that discharges food donors' liability after they make donations. This means that enterprises cannot donate food at will. A news story entitled "incineration of food surplus as waste", reported by Taiwan's media in 2011, aroused people's doubts as to whether the food surplus recycling policy introduced by the government is practically being implemented. In addition, a high water content will lead to the incomplete incineration of waste, thus generating a large amount of dioxin and therefore causing environmental pollution.

Currently, "food banks" in various regions of Taiwan are able to accept food donations, such as the "Taiwan HLIC Foodbank", Andrew Food Bank, and 1919 Food Bank. The purpose of operating such food banks is to provide underprivileged groups with relief supplies, but those in need often encounter difficulties during the application process, and in addition, legal protection is not provided to enterprises that donate supplies, and there is no solid platform to allow public and private sectors to work together. Food banks in Taiwan are subject to the following defects. First, there is an emphasis on administrative procedures; food can be collected only when applications are approved. Food collection falls within the "forced collection" criteria. "Forced collection" refers to food banks distributing food packages to those whose applications have been approved no matter what, i.e., whether the applicant needs food now or not. Second, enterprises are currently only protected by Civil Law, Article 411, which provides that "the donor is not liable for a defect in the thing or right given". However, if he/she has intentionally concealed the defect or expressly guaranteed that the thing was free from such a defect, he/she is bound to compensate the recipient for any injury arising therefrom." The sentence "the donor is not liable for a defect in the thing or right given" is only a concept of exemption, which is not enough motivation for enterprises to feel confident in making donations. Third, there is no platform to combine the efforts of the public and private sectors; therefore, the whole operational system fails to run smoothly due to various issues, including transportation, human resources training, diversity and 
safety of food, and unclear definition of roles. In such cases, not only are people in need unable to receive substantial assistance, but food that could have been utilized often has to be discarded.

The most representative non-governmental organization committed to saving food surplus is "Chi-his Kitchen", which was founded by Chi-his Yang for the original purpose of addressing food waste issues caused by vegetables being discarded in markets only because of appearance and turning such discarded vegetables into meals for those in need in the community without cost. "Food Sharing Taiwan", derived from the phrase "Food Sharing" and inspired by a movement in Germany, is committed to saving overproduced food. This organization fully relies on support from the public to operate, without any other kinds of support, such as sponsorship from enterprises or government. Stores with a large amount of unsold food can provide such food to those in need through this platform. This platform has set "food sharing refrigerators" along the streets, which is a kind and gratis act, with no responsibility to test and maintain the food quality. Takers need to interpret the quality of food on their own and agree to the risks of eating it. "Foodify", an online platform developed by students of Tsinghua University, is dedicated to connecting the locations of available food surplus. Users can exchange food with others or buy food at a lower price on this platform after simple registration, which could help retailers or people who have bought too much food to reduce food waste in a mutually beneficial manner.

In general, the results of this study show that significant effort is still needed in relation to the sharing economy, economic sustainability, and environmental sustainability in Taiwan. The actions taken by Europe and the UK can be models for our reference. On the other hand, the sharing economy, economic sustainability, and environmental sustainability are issues that further studies need to work on at the local level. Fortunately, some researchers have already published findings regarding food surplus/waste, the sharing economy, economic sustainability, and environmental sustainability $[27,47,48]$.

\section{Conclusions}

The results verified that food waste and food surplus are vital issues for many countries around the world. This study also found out that there are a number of organizations globally that are focused on the issues of food surplus and food waste. Apart from food waste and food surplus, the results showed some other terms that tend to appear in articles on these issues, including food waste, production, food surplus, management, countries, environmental, consumption, household, world, and economic. It is obvious that they are important factors in the issues of food waste and food surplus. Other additional terms include sustainable, energy, research, agricultural, international, consumer, anaerobic, global, resources, digestion, university, and prevention. This confirmed the usefulness of using economic sustainability, environmental sustainability, and the sharing economy as factors for analysis in this study. Although publications or articles related to the issues of sustainability in food waste and surplus are still uncommon, this study shows that studying food waste from the aspects of the sharing economy, economic sustainability, and environmental sustainability is necessary.

The results also found that regulated sustainability has received attention in some countries. Based on the discussion of a case in Taiwan, governments have started to advocate reducing food waste, tracking food surplus by regulatory intervention according to sustainability regulations, and trying to solve problems in terms of unfair effects caused by the sharing economy, although regulated sustainability and the sharing economy are contradictory in some ways. According to Figure 9, the sharing economy and policy are two of the more decentralized and equitable forms of consumption and are pathways to handle the economic sustainability and environmental sustainability crisis; they are furthermore related to the terms "policy" and "FAO". The regimes of regulated sustainability should be disrupted in order to frame a common vision of the sharing economy, which is a niche of innovation. The imperative issue of economic growth might sacrifice environmental sustainability. Based on the other terms found in the results, there are a number of societal challenges related to promoting and achieving environmental sustainability and economic sustainability. Although the 
environmental benefits of the sharing economy are quite significant, it is extremely complicated and challenging to demonstrate environmental sustainability at the aggregate levels and based on the net impacts.

This study also aimed to find the connections between food waste and food surplus in the hospitality industry and found some evidence in industry from the results. The purpose of this research was to assist and provide effective management strategies to operators in the hospitality industry in Taiwan and, moreover, to address food waste and food surplus issues in order to acquire a better understanding through execution and promotion periods; for example, sharing of the food surplus with those in need through establishing restaurant food surplus information exchange platforms in the future. The research results of this study may enable subsequent experts and scholars to form advanced research plans, which in turn can attract government attention towards related policies that could be developed to reduce food waste and surplus, and could also encourage industries, government, universities, and non-governmental organizations from different fields to make joint contributions to address food waste and food surplus. It is expected that society will work as a whole towards more sustainable food production and processes.

Author Contributions: Conceptualization, C.-H.H.; methodology, C.-H.H.; software, S.-M.L.; validation, C.-H.H.; formal analysis, C.-H.H. and S.-M.L.; investigation, C.-H.H., and N.-Y.H.; resources, C.-H.H.; data curation, C.-H.H. and N.-Y.H.; writing - original draft preparation, C.-H.H.; writing-review and editing, C.-H.H., S.-M.L., and N.-Y.H.; visualization, C.-H.H.; supervision, C.-H.H.; project administration, C.-H.H.; funding acquisition, C.-H.H. All authors have read and agree to the published version of the manuscript.

Funding: This research was funded by Ministry of Science and Technology (MOST), Taiwan, grant number MOST108-2410-H-020-008-.

Acknowledgments: The authors are immensely grateful to MOST, Taiwan for supporting in all our research publications and outputs. We also appreciate 3 anonymous reviewers and editor for the comments that greatly improved the manuscript.

Conflicts of Interest: The authors declare no conflict of interest.

\section{References}

1. FAO. Global Food Losses and Food Waste-Extent, Causes and Prevention. 2011. Available online: http://www.fao.org/3/a-i2697e.pdf (accessed on 18 February 2020).

2. Godfray, H.C.J; Beddington, J.R.; Crute, I.R.; Haddad, L.; Lawrence, D.; Muir, J.F.; Toulmin, C. Food security: The challenge of feeding 9 billion people. Science 2010, 327, 812-818. [CrossRef] [PubMed]

3. Hic, C.; Pradhan, P.; Rybski, D.; Kropp, J.P. Food surplus and its climate burdens. Environ. Sci. Technol. 2016, 50, 4269-4277. [CrossRef] [PubMed]

4. Dion, C. Demain: Un Nouveau Monde en Marche; Éditions Actes Sud: Arles, France, 2015.

5. FAO. Global Initiativeon Food Loss and Waste Reduction. 2015. Available online: http://www.fao.org/3/ai4068e.pdf (accessed on 18 February 2020).

6. Papargyropoulou, E.; Lozano, R.; Steinberger, J.K.; Wright, N.; bin Ujang, Z. The food waste hierarchy as a framework for the management of food surplus and food waste. Clean. Prod. 2014, 76, 106-115. [CrossRef]

7. Principato, L.; Pratesi, C.A.; Secondi, L. Towards Zero Waste: An Exploratory Study on Restaurant managers. Int. J. Hosp. Manag. 2018, 74, 130-137. [CrossRef]

8. Heikkilä, L.; Reinikainen, A.; Katajajuuri, J.M.; Silvennoinen, K.; Hartikainen, H. Elements affecting food waste in the food service sector. Waste Manag. 2016, 56, 446-453. [CrossRef] [PubMed]

9. Pham Phu, S.T.; Hoang, M.G.; Fujiwara, T. Analyzing solid waste management practices for the hotel industry. Glob. J. Environ. Sci. Manag. 2018, 4, 19-30.

10. Aschemann-Witzel, J.; de Hooge, I.; Amani, P.; Bech-Larsen, T.; Oostindjer, M. Consumer-related food waste: Causes and potential foraction. Sustainability 2015, 7, 6457-6477. [CrossRef]

11. Pirani, S.I.; Arafat, H.A. Solid waste management in the hospitality industry: A review. Environ. Manag. 2014, 146, 320-336. [CrossRef] 
12. Papargyropoulou, E.; Wright, N.; Lozano, R.; Steinberger, J.; Padfield, R.; Ujang, Z.J. Conceptual framework for the study of food waste generation and prevention in the hospitality sector. Waste Manag. 2016, 49, 326-336. [CrossRef]

13. Pirani, S.I.; Arafat, H.A. Reduction of food waste generation in the hospitality industry. Clean. Prod. 2016, 132, 129-145. [CrossRef]

14. Kallbekken, S.; Sælen, H. 'Nudging' hotel guests to reduce food waste as a win-win environmental measure. Econ. Lett. 2013, 119, 325-327. [CrossRef]

15. Kuczman, O.; Gueri, M.V.D.; De Souza, S.N.M.; Schirmer, W.N.; Alves, H.J.; Secco, D.; Hernandes, F.B. Food waste anaerobic digestion of a popular restaurant in Southern Brazil. J. Clean. Prod. 2018, 196, 382-389. [CrossRef]

16. Selin, J. Towards Reducing Food Waste in a Hotel Breakfast Buffet: A Case Study of Profil Hotels Calmar Stadshotell. Master's Thesis, Linnaeus University, Växjö, Sweden, 2018. Unpublished.

17. Sakaguchi, L.; Pak, N.; Potts, M.D. Tackling the issue of food waste in restaurants: Options for measurement method, reduction and behavioral change. Clean. Prod. 2018, 180, 430-436. [CrossRef]

18. Eriksson, M.; Osowski, C.P.; Malefors, C.; Björkman, J.; Eriksson, E. Quantification of food waste in public catering services-A case study from a Swedish municipality. Waste Manag. 2017, 61, 415-422. [CrossRef] [PubMed]

19. Stöckli, S.; Dorn, M.; Liechti, S. Normative prompts reduce consumer food waste in restaurants. Waste Manag. 2018, 77, 532-536. [CrossRef] [PubMed]

20. Fieschi, M.; Pretato, U. Role of compostable tableware in food service and waste management. A life cycle assessment study. Waste Manag. 2017, 73, 14-25. [CrossRef]

21. Wang, L.E.; Liu, G.; Liu, X.; Liu, Y.; Gao, J.; Zhou, B.; Cheng, S. The weight of unfinished plate: A survey based characterization of restaurant food waste in Chinese cities. Waste Manag. 2017, 66, 3-12. [CrossRef]

22. Filimonau, V.; Lemmer, C.; Marshall, D.; Bejjani, G. 'Nudging' as an architect of more responsible consumer choice in food service provision: The role of restaurant menu design. Clean. Prod. 2017, 144, 161-170. [CrossRef]

23. Hamerman, E.; Rudell, F.; Martins, C.M. Factors that predict taking restaurant leftovers: Strategies for reducing food waste. Consum. Behav. 2017, 17, 94-104. [CrossRef]

24. Richards, T.J.; Hamilton, S.F. Food waste in the sharing economy. Food Policy 2018, 75, 109-123. [CrossRef]

25. Heo, Y. Sharing economy and prospects in tourism research. Ann. Tour. Res. 2016, 58, 166-170. [CrossRef]

26. Morone, P.; Papendiek, F.; Tartiu, V.E. Food Waste Reduction and Valorisation; Springer: Berlin, Germany, 2017.

27. Michelini, L.; Principato, L.; Iasevoli, G. Understanding food sharing models to tackle sustainability challenges. Ecol. Econ. 2018, 145, 205-217. [CrossRef]

28. Falcone, P.M.; Imbert, E. Bringing a sharing economy approach into the food sector: The potential of food sharing for reducing food waste. In Food Waste Reduction and Valorisation; Springer: Berlin, Germany, 2017; pp. 197-214.

29. Morone, P.; Falcone, P.M.; Imbert, E.; Morone, M.; Morone, A. Tackling Food Waste through a Sharing Economy Approach: An Experimental Analysis. MPRA Working Papers. 2016. Available online: https: //mpra.ub.uni-muenchen.de/70626/ (accessed on 18 February 2020).

30. Moretti, F.; van Vliet, L.; Bensing, J.; Deledda, G.; Mazzi, M.; Rimondini, M.; Fletcher, I. A standardized approach to qualitative content analysis of focus group discussions from different countries. Patient Educ. Counse. 2011, 82, 420-428. [CrossRef] [PubMed]

31. Humphreys, A.; Wang, R.J.H. Automated text analysis for consumer research. J. Consum. Res. 2018, 44, 1274-1306. [CrossRef]

32. Elo, S.; Kääriäinen, M.; Kanste, O.; Pölkki, T.; Utriainen, K.; Kyngäs, H. Qualitative content analysis: A focus on trustworthiness. SAGE Open 2014, 4, 1-10. [CrossRef]

33. Edhlund, B.; McDougall, A. NVivo 12 Essentials; Lulu Press: Morrisville, CA, USA, 2019.

34. De Swert, K. Calculating inter-coder reliability in media content analysis using Krippendorff's Alpha. Cent. Politics Commun. 2012. Available online: http://www.polcomm.org/wp-content/uploads/ICR01022012. pdf (accessed on 18 February 2020).

35. Landis, J.; Koch, G. The measurement of observer agreement for categorical data. Biometrics 1977, 33, $159-174$. [CrossRef] 
36. The Guardian. French Law Forbids Food Waste by Supermarkets. Available online: https://www.theguardian. com/world/2016/feb/04/french-law-forbids-food-waste-by-supermarkets (accessed on 4 February 2016).

37. BBC News. Italy Adopts New Law to Slash Food Waste. Available online: https://www.bbc.com/news/ world-europe-36965671 (accessed on 18 October 2016).

38. Retail Detail. German Minister Wants to Remove "Best Before Date". Available online: https://www. retaildetail.eu/en/news/german-minister-wants-remove-best-date (accessed on 4 December 2016).

39. FoodCloud. The Problem. Available online: https://food.cloud/the-problem/ (accessed on 2 December 2018).

40. Stenmarck, Å.; Jensen, C.; Quested, T.; Moates, G. Estimates of European Food Waste Levels; EU FUSION: Stockholm, Sweden, 2016; Volume 20.

41. ADEME. Food Losses and Waste-Inventory and Management at Each Stage in the Food Chain Executive Summary. 2016. Available online: https://www.ademe.fr/sites/default/files/assets/documents/food-losseswaste-inventory-management-2016-summary.pdf (accessed on 18 February 2020).

42. Setti, M.; Falasconi, L.; Segrè, A.; Cusano, I.; Vittuari, M. Italian consumers' income and food waste behavior. Br. Food J. 2016, 118, 1731-1746. [CrossRef]

43. Hermsdorf, D.; Rombach, M.; Bitsch, V. Food waste reduction practices in German food retail. Br. Food J. 2017, 119, 2532-2546. [CrossRef]

44. Gunders, D.; Jonathan, B. Wasted: How America is losing up to 40 percent of its food from farm to fork to landfill; Natural Resources Defense Council: New York, NY, USA, 2017.

45. FAO. Food Wastage Footprint: Impact on Natural Resources Report. 2013. Available online: http: //www.fao.org/3/i3347e/i3347e.pdf (accessed on 18 February 2020).

46. Mourad, M. Recycling, recovering and preventing "food waste": Competing solutions for food systems sustainability in the United States and France. J. Clean. Prod. 2016, 126, 461-477. [CrossRef]

47. Martin, C.J. The sharing economy: A pathway to sustainability or a nightmarish form of neoliberal capitalism? Ecol. Econ. 2016, 121, 149-159. [CrossRef]

48. Schor, J.; Debating the Sharing Economy. Great Transformation Initiative. 2014. Available online: http: //greattransition.org/publication/debating-the-sharing-economy (accessed on 18 February 2020).

(C) 2020 by the authors. Licensee MDPI, Basel, Switzerland. This article is an open access article distributed under the terms and conditions of the Creative Commons Attribution (CC BY) license (http://creativecommons.org/licenses/by/4.0/). 